\title{
Agonistic behaviour of Scarites buparius (Forster, 1771) (Coleoptera: Carabidae) in relation to body size
}

\author{
Teresa Bonacci, Pietro Brandmayr, Anita Giglio, Alessandro Massolo, Antonio Mazzei, \\ Rosalba Odoguardi, Mariastella Romeo, Federica F. Talarico \& Tullia Zetto Brandmayr*
}

\begin{abstract}
Bonacci, T., Brandmayr, P., Giglio, A., Massolo, A., Mazzei, A., Odoguardi, R., Romeo, M., Talarico, F. F. \& Brandmayr, T. Z. 2006: Agonistic behaviour of Scarites buparius (Forster, 1771) (Coleoptera: Carabidae) in relation to body size. Entomol. Fennica 17: 340-344.

Intra-male aggressive behaviour of Scarites buparius was analysed; agonistic interaction between males consisted of a repeated series of fighting events. We defined this behaviour as "agonistic" because a dominance/submission status was established. We measured the males and found that the attack behaviour persistence is correlated with the body length.

T. Bonacci, P. Brandmayr, A. Giglio, A. Mazzei, R. Odoguardi, M. Romeo, F. F. Talarico and T. Z. Brandmayr, Dipartimento di Ecologia, Università degli Studi della Calabria, 87036 Rende (CS), Italy; *correspondent author's e-mail: tuzetto@unical.it

A. Massolo, Dipartimento di Biologia Animale e Genetica, Università di Firenze, via Romana, 17, I-50125 Firenze, Italy
\end{abstract}

Received 12 December 2005, accepted 22 May 2006

\section{Introduction}

In the sense of King (1973), "agonistic behaviour" includes all behaviours associated with the struggle between individuals of the same species. The motor or action patterns in the predator-prey encounter or in inter-specific competition are often the same as those exhibited between conspecific rivals. The behaviour is similar, but the function of the agonistic behaviour changes from inter-specific competition and predator-prey relationships to intra-specific sociality. Usually, losers in the agonistic encounter are variously opposed, depending on the species; conversely winners gain social status or access to resources. The evolution of restraints to high aggressiveness may buffer a strong negative outcome for the loser.
Agonistic behaviour is an inherent capacity of most animals. For invertebrates it has been studied in spiders (Austad 1982, 1983, Leimar et al. 1991), cuttlefish and squid (Adamo \& Hanlon 1996, King et al. 2003), scorpion flies (Thornill 1984) and most exhaustively in crustaceans (Hazlett 1981, 1999, Bruski \& Dunham 1987, Copp 1986, Daws et al. 2002, Gherardi \& Pieraccini 2004, Goessmann et al. 2000, Guiasu \& Dunham 1997, Karavanich \& Atema 1998). Usually, agonistic behaviour is triggered by the competition for resources (reproduction, feeding, territory or many among them) and it seems to increase with the population density (Hazlett 1968), and the dominants might hypothetically occupy most of the niche space if resources are in low density (Levins 1968). Morse (1974) found that the dominant individuals have larger body 
size than subordinates in most hierarchies. In insects, size is an important characteristic determining reproductive success in males (McLain 1982). In soldier beetles higher success in obtaining mates is positively correlated with antennal scape diameter (Mason 1980). Positively variation in male dry weight and diameter of antennae and palpi in Meloidae (Coleoptera) may cause an increasing of the courtship duration (McLain 1982).

Agonistic behaviour in Coleopterans has been poorly investigated; particularly for carabid beetles. S. buparius is one of the first species for which intramale fighting has been reported both in the field and in the laboratory (Alicata et al. 1980). Recently, Mossakowski (2003) studied the fighting behaviour of Broscus cephalotes (L.). In this paper we describe the intramale agonistic behaviour and its repertoire of interactions.

\section{Material and methods}

Sixteen specimens (4 females and 12 males) of S. buparius, collected in sand dune habitats on the Ionian sea coast, Squillace, Italy, were separately kept in glass containers (diameter $5.5 \mathrm{~cm}, 8 \mathrm{~cm}$ tall), with $2 \mathrm{~cm}$ of sandy soil, in a climatic chamber at day/night $\mathrm{T} 24^{\circ} \mathrm{C} / 18^{\circ} \mathrm{C}$, under $\mathrm{L} / \mathrm{D}: 12 / 12$ photoperiod and fed on Theba pisana (Gastropoda) collected in the same habitats.

\subsection{Behavioural analysis}

Each dyad of $S$. buparius was tested in the laboratory (35 recording sessions in total) for $30 \mathrm{~min}-$ utes. Animals were fairly fed before the experiment. In each test one specimen was marked with non-toxic paint. The experimental arena was a glass container with a plaster substrate $(8.5 \mathrm{~cm} \times$ $5.5 \mathrm{~cm}$ ); the test started when both specimens were placed inside.

The behaviour was recorded by digital video equipment (Sony digital video camera and a DVD recorder) and behavioural analyses were carried out with software for behavioural research (The Observer ${ }^{\circledR}$ version 2.0, University of
Kiel, Germany). Data analysis (frequency and sequence of events) was performed with the software The Observer.

\subsection{Morphometric analysis}

The sample consisted of 16 individuals of Scarites buparius. Magnified images were taken by mean of a stereoscope (Zeiss Stemi SV $11 \mathrm{Apo}$ ), and image capture was performed using the software Matrox PC-VCR (Windows 2000). For each individual, we measured body length $(\mathrm{mm})$, mandible length $(\mathrm{mm})$, head length $(\mathrm{mm})$, head width $(\mathrm{mm})$, pronotum length $(\mathrm{mm})$, pronotum width $(\mathrm{mm})$ and elytral length $(\mathrm{mm})$. Measurements were taken using Sigma Scan Pro 5 software (SPSS ${ }^{\circledR}$ Inc.).

\subsection{Statistical analysis}

The relationship between morphometric measurements and agonistic behaviour events was analysed by logistic regression (Hosmer \& Lemeshow 1989).

We used the Spearman correlation coefficient to test for association between the duration of aggressive behaviour and body size (Siegel \& Castellan 1998), and then we used nonlinear curve estimation to compare the fitting of different equations (Linear, power, exponential, logarithmic, inverse) (SPSS ${ }^{\circledR}$ Base 12.0 User's Guide 2003).

All statistical analyses were performed with the Statistical Package for Social Sciences, version $12.01\left(\mathrm{SPSS}^{\circledR}\right)$.

\section{Results}

After the introduction into the experimental arena, the beetles exhibited aggressive behaviour with a typical repertoire of eleven interactions (events).

(1) Latency of attack: the time passing from the introduction into the arena to the attack of one of the two rivals (Frequency of occur- 

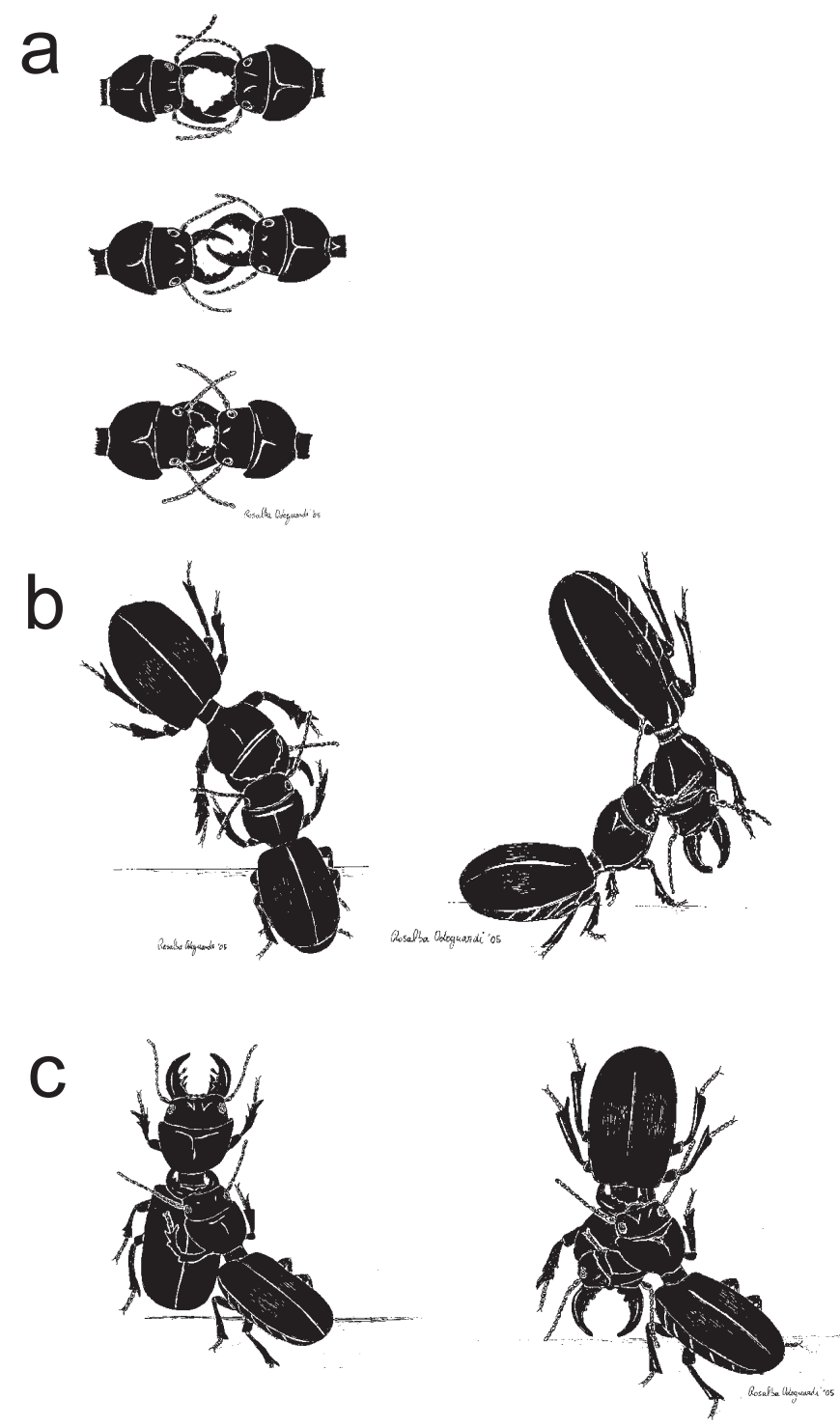

Fig. 1. Agonistic repertoire in Scarites buparius (observed behavioural events). - a. Mandible grip: one individual grasps the other by its mandibles. This grip involves the contact of antennae. - b. Head-pronotum grip: one individual grasps the other by the neck (left) or by the pronotum (right). - c. Pronotumabdomen grip: one individual grasps the other by the
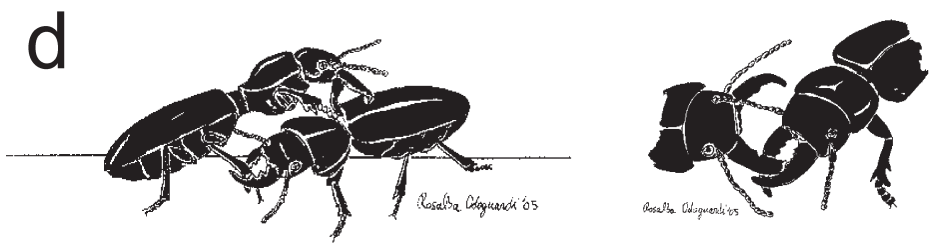
mesonotum. The subordinate individual may be raised head-up (left) or head-down (right). - d. Defensive grip: the subordinate individual grasps with mandibles the other on the leg or by the mandibles.

rence $\left.\left(\mathrm{F}_{\mathrm{o}}\right)=34 ; \overline{\mathrm{x}}=293.34 \pm 370.67 \mathrm{sec}\right)$.

(2) Attack: one individual advances towards the other with opened mandibles gripping the opponent's body $\left(\mathrm{F}_{\mathrm{o}}=648 ; \overline{\mathrm{x}}=8.24 \pm 8.31\right.$ $\mathrm{sec})$. The event "grip" during the agonistic behaviour was carried out by means of three items (mandible grip, head/pronotum grip, pronotum/abdomen grip).

(3) Mandible grip: one individual grasps the other by its mandibles. This behavioural 
event involves the contact of antennae $\left(\mathrm{F}_{\mathrm{o}}=\right.$ $142 ; \overline{\mathrm{x}}=21.92 \pm 72.48$ ) (Fig. 1a).

(4) Head-pronotum grip: most frequently the dominant grasps the subordinate individual by the head/pronotum articulation (a) or by the pronotum $(\mathrm{b})\left(\mathrm{F}_{\mathrm{o}}=149 ; \overline{\mathrm{x}}=21.71 \pm 26.69\right)$ (Fig. 1b).

(5) Pronotum - abdomen grip: one individual grasps the other by the mesonotum. The subordinate individual may be raised head-up (a) or head-down (b); $\left(\mathrm{F}_{\mathrm{o}}=133 ; \overline{\mathrm{x}}=36.05 \pm\right.$ $98.62 \mathrm{sec}$ ) (Fig. 1c).

(6) Grip-raising: one individual grasps the other with the mandibles and raises it from the substrate $\left(\mathrm{F}_{\mathrm{o}}=256 ; \overline{\mathrm{x}}=26.26 \pm 16.52 \mathrm{sec}\right)$.

(7) Defensive grip: the subordinate individual grasps with mandibles the other on the leg or on the mandibles $\left(\mathrm{F}_{\mathrm{o}}=82 ; \overline{\mathrm{x}}=5.65 \pm 11.75\right.$ sec) (Fig. 1d).

(8) Skipping: this event was displayed only by the dominant individual; it skips without moving from its position $\left(\mathrm{F}_{\mathrm{o}}=138 ; \overline{\mathrm{x}}=9.99 \pm\right.$ $24.03 \mathrm{sec})$.

(9) Immobility: the subordinate during the grip remains motionless $\left(\mathrm{F}_{\mathrm{o}}=219 ; \overline{\mathrm{x}}=42.97 \pm\right.$ $96.08 \mathrm{sec}$ ).

(10)Antennal contact: during the fight the individuals interact via their antennae $\left(\mathrm{F}_{\mathrm{o}}=150\right.$; $\overline{\mathrm{x}}=24.55 \pm 36.67 \mathrm{sec}$ ).

(11)Escape movement: one individual, during an aggressive behaviour episode, escapes $\left(\mathrm{F}_{\mathrm{o}}=\right.$ $590 ; \bar{x}=8.2 \pm 4.22 \mathrm{sec}$ ).

Our data showed a significant relation between dominant and subordinate specimens. Pronotum length $(B=28.390 ; p=0.041)$, pronotum width $(B=35.839 ; p=0.021)$ and total body length $(B=$ $60.803 ; p=0.027)$ influenced significantly the acquisition of the dominance-status. Duration of aggressive behaviour was positively correlated with total body length $(r=0.589, p<0.001)$, confirmed by a significant exponential fitting $\left(R^{2}=\right.$ 0.334, $b_{1}=0.594, p<0.001$; Fig. 2).

\section{Discussion}

In this paper we analysed the fighting behaviour of $S$. buparius. In this carabid beetle the aggressiveness involves some important phases: "at-

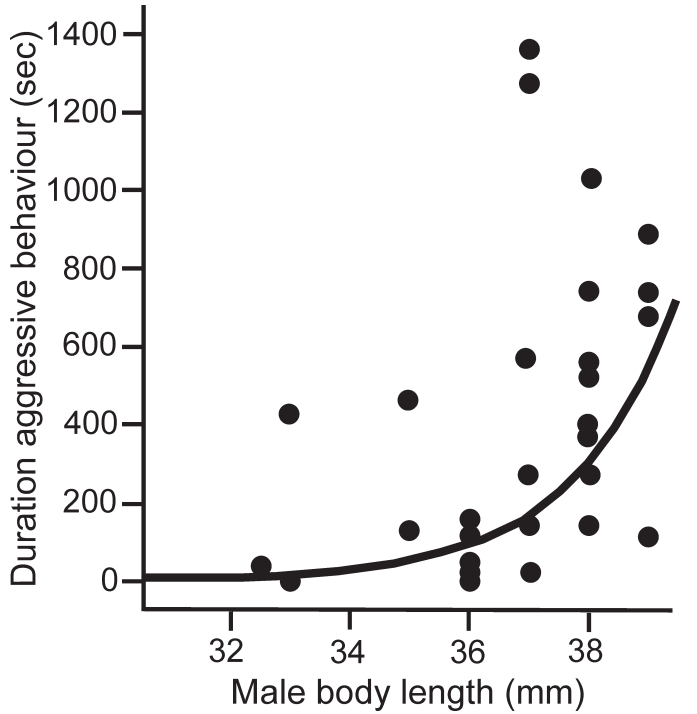

Fig. 2. Relationship between male body length of Scarites buparius and duration of male aggressive behaviour in the laboratory. Black dots = behavioural test events; curve = exponential curve.

tack", one individual approaches the other with opened mandibles to grip the antagonist's body; "mandible grip", one individual grasps the other by the mandibles, while a rapid antennation occurs between the two individuals; "grip", one individual grasps the other by various parts of its body.

Throughout the agonistic behaviour, S. buparius specimens establish the dominant/subordinate status. Dominants show superior body strength; in particular, they have larger body length and a wider and longer pronotum. The dominant individual attacks and raises subordinates more frequently but it never injures the rival severely. Conversely, subordinates suffer the attack without an aggressive reaction. It is likely that male aggressive behaviour in $S$. buparius involves reproductive fitness, as vigorous males increase the probability to fertilize a large number of females.

The body size of arthropods may even determine the result of agonistic encounters between males (Austad 1983, Suter 1990) and, as a consequence, the fecundity of the interacting males.

Significant correlations between size of male and its reproductive success were also found by McLain (1982) in Epicauta pennsylvanica (Cole- 
optera, Meloidae); larger male size has been associated with higher competitive ability or success in obtaining mates in a variety of beetles (Brown 1980, Otte \& Joern 1975).

During the different phases of the agonistic behaviour, the beetles continuously interact via their antennae. Our hypothesis is that this behaviour may play a role in the inhibition of aggressiveness since a great deal of information is probably transferred during this antennal display about the conspecific recognition.

\section{References}

Adamo, S. A. \& Hanlon, R. T. 1996: Do cuttlefish (Cephalopoda) signal their intentions to conspecific during agonistic encounters? - Animal Behaviour 52: 7381

Alicata, P., Caruso, D., Costa, G., Marcellino, I., Motta, S. \& Petralia, A. 1980: Ricerche eco-etologiche sulla fauna delle dune costiere di Portopalo (Siracusa). III. Comportamento e ritmi di attività di Scarites buparius FORST. (Coleoptera, Carabidae). - Animalia 7 (1/3): 5-21.

Austad, S. N. 1982: First male sperm priority in the bowl and doily spider, Frontinella pyramitela (Walckenaer). - Evolution 34(4): 777-785.

Austad, S. N. 1983: A game theoretical interpretation of male combat in the bowl and doily spider (Frontinella pyramitela). — Animal Behaviour 31: 59-73.

Brown, L. 1980: Aggression and mating success in males of the forked fungus beetle, Bolitotrerus cornutus (Panzer) (Coleoptera: Tenebrionidae). — Proceedings of the Entomological Society of Washington 82: 430 434.

Bruski, C. \& Dunham, D. W. 1987: The importance of vision in agonistic communication of the crayfish Orconectes rusticus. An analysis of bout dynamics. Behaviour 103: 83-107.

Copp, N. 1986: Dominance hierarchies in the crayfish Procambarus clarkii and the question of learned individual recognition. - Crustaceana 51: 9-24.

Daws, A. G., Grills J., Konzen, K. \& Moore, P. A. 2002: Previous experiences alter the outcome of aggressive interactions between males in the crayfish, Procambarus clarkii. - Marine and Freshwater Behaviour and Physiology 35: 139-148.

Gherardi, F. \& Pieraccini, R. 2004: Using information theory to assess dynamics, structure, and organization of crayfish agonistic repertoire. - Behavioural Processes 65: 163-178.

Goessmann,, C., Hemerlrijk, C. \& Huber, R. 2000: The formation and maintenance of crayfish hierarchies: behavioral and self-structuring properties. - Behav- ioural Ecology and Sociobiology 48: 418-428.

Guiasu, R. C. \& Dunham, D. W. 1997: Initiation and outcome of agonistic contests in male form in Cambarus robustus Girard, 1852 crayfish (Decapoda, Cambaridae). - Crustaceana 70: 720-736.

Hazlett, B. A. 1968: Effects of crowding on the agonistic behaviour of the hermit crab Pagurus bernhardus. Ecology 49(3): 573-575.

Hazlett, B. A. 1981: The behavioral ecology of hermit crabs. - Annual Review of Ecology and Systematics 12: 1-22.

Hazlett, B. A. 1999: Responses to multiple chemical cues by the crayfish Orconectes virilis. - Behaviour 136 : 161-177.

Hosmer, D. W. \& Lemeshow, S. 1989: Applied Logistic Regression. - John Wiley \& Sons, New York, USA.

Karavanich, C. \& Atema, J. 1998: Individual recognition and memory in lobster dominance. - Animal Behaviour 56: $1553-1560$.

King, J.A. 1973: The ecology of aggressive behavior. Annual Review of Ecology and Systematics 4: 117138.

King, A.J., Adamo, S.A. \& Halon, R.T. 2003: Squid egg mops provide sensory cues for increased agonistic behaviour between male squid. - Animal Behaviour 66: 49-58.

Leimar, O. Austad, S. \& Equist, M. 1991: A test of the sequential assessment game: fighting in the bowl and doily spider Frontinella pyramitela. - Evolution 45 (4): 862-874.

Levins, R. 1968: Evolution in changing environments. Monographs of Population Biology 2: 1-120.

Mason, L. G. 1980: Sexual selection and the evolution of pair bonding in soldier beetles. — Evolution 34: 174 180.

McLain, D. K. 1982: Behavioral and morphological correlates of male dominance and courtship persistence in the blister beetle Epicauta pennsylvanica (Coleoptera: Meloidae). - American Midland Naturalist 107 (2): 396-403.

Morse, D.E. 1974: Niche breadth as a function of social dominance. - The American Naturalist 108 (964): 818-830.

Mossakowski, D. 2003: Feeding and fighting behavior in Broscus cephalotes (L.). — Baltic Journal of Coleopterology 3 (2): 173-176.

Otte, D. \& Joern, A. 1975: Insects territoriality and its evolution: population studies of desert grasshoppers on creosote bushes. - Journal of Animal Ecology 44(1): 29-54.

Siegel, S. \& Castellan, N. J. J. 1988: Nonparametric statistics for the behavioral sciences. - Mcgraw-Hill, New York, USA.

Suter, R. B. 1990: Determinants of fecundity in Frontinella pyramitela (Araneae, Linyphiidae). - Journal of Arachnology 18: 263-269.

Thornhill, R. 1984: Fighting and assessment in Harpobittacus scorpionflies. — Evolution 31(1): 204-214. 